\title{
التنمية السياحية المتواصلة من منظور علاقاتها بالبيئة
}

* ايمان محمد عبد الفتاح منجى

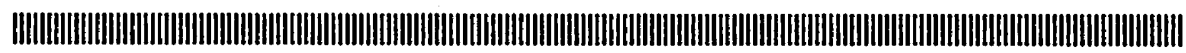

يعتبر قطاع السياحة من القطاعات الاستراتيـجية الهامة التى تعمل الدولة على تنميتها وذلك لما له من تأثيرات مباشرة وغير مباشرة على القطاعات الاقتصادية المتختلفة. وفى سبيل تنميه حقيقيـة متواصلة لهذا القطاع الحيوى كان لابد من دراسة الارتباط الوثيت بين السياحة والبيئة بأنظمتها الطبيعية والمصنوعة والاجتماعية والتأثيرات المتبادلة بينهما . وتتعرض هذه الدارسة لموضوع ارتباط السياحة بالبيئة وتأثيراتهما المتبادلة وانعكاس ذلل على مسيرة التنمية · ولتحقيق هذا الهدف تتناول الدراسة النقاط التالية : أولا :- أهمية قطاع السياحة من الناحية الاقتصادية والاجتماعية . ثانيا :- العلاقات التأثيرية المتبادلة بين السياحة والبيئة . ثالدا :- تحليل العلاقة بين البيئة والمغريات السياحية . رابعا :- الأزمات البيئية وعلاقتها بالسياحة فى ج •م·ع خامسا :- التنمية السياحية المتواصلة (المستدامة) . سادسا :-- أهمية الوعى البينى كمدخل للتنمية السياحية .

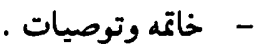

* د. ايمان محمد عبد الفتاح منجى خبير بمركز التخطيط الاجتماعى والثقافى - معهد التخطيط القومى. 
أولا :- أهية قطاع السياحة من الناحية الاقتصادية والاجتماعية

تعتبر السياحة أحد القطاعات التى تَتد آثار نموها لأجيال طويلة نظرا لارتفاع مرونة الطلب

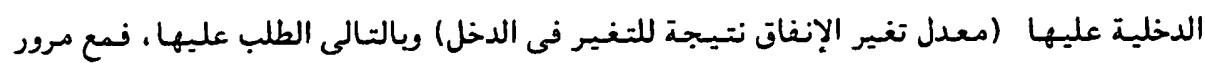

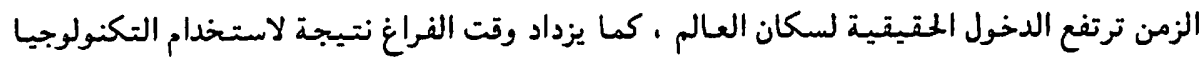

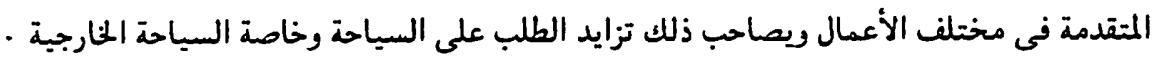
ويعتبر توافر مقومات الجذبب السياحى من ثروات طبيعية وآثار وخدمات سياحية ، واستقرار

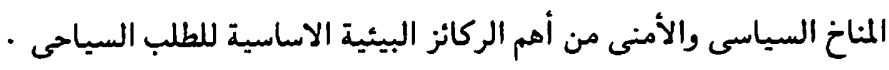

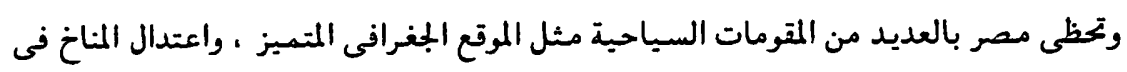

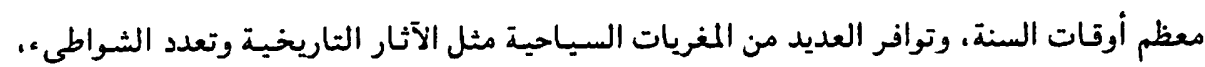
وأماكن الاستشفاء والأماكن الترفيهية وكلها عوامل جذب للسائحين. ولكن بالرغم من هذه المقومات فلم تحظ مصر بالمكانة التى يجب أن تتبوؤها سياحيبا وذلك

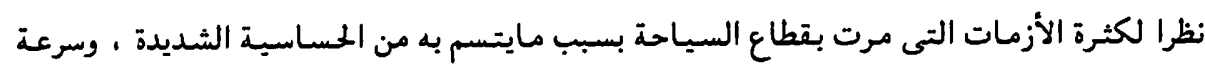
التأثر بالأزمات الترة الترمات

وترجع الأهمية الاتتصادية لقطاع السياحة فى تأثيره المباشر أو غبر المباشر على القطاعات

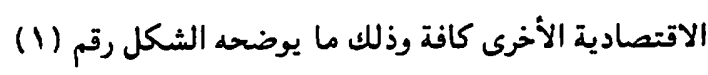

شكل رقم (1)

تأثير قطاع السياحة على القطاعات الاقتصادية المختلفة

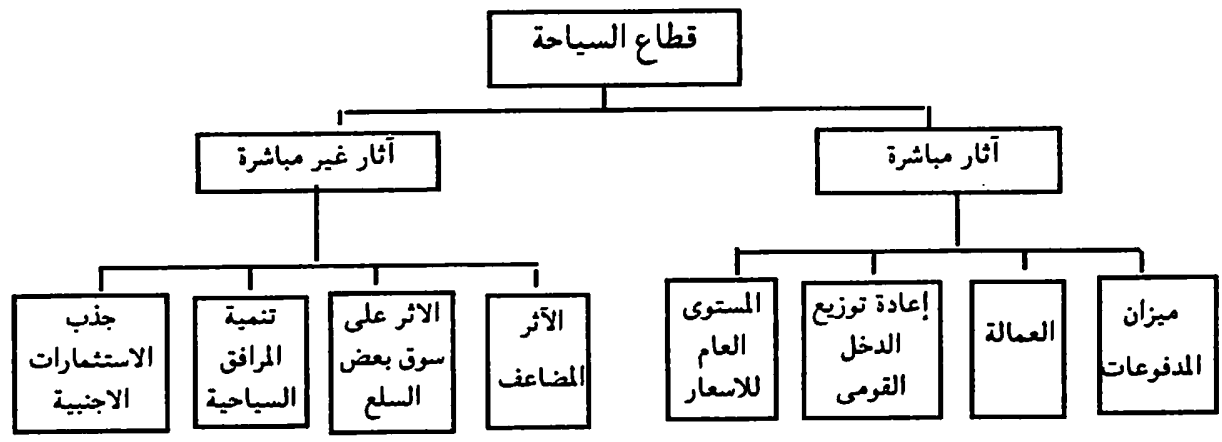

المسر: (من إعداد الباحثة) 
الآثار المباشرة لقطاع السياحة

1 - السباحة وميزان المدفوعات :

تقاس الأهمية الاقتصادية للسياحة بآثارها على ميزان المدفوعات من خلال الإيرادات السياحية

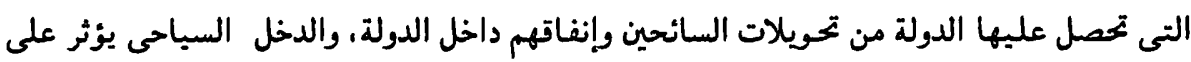

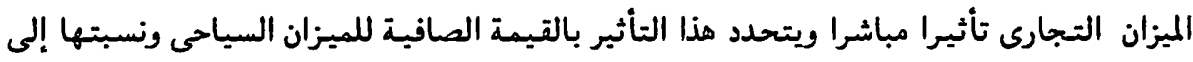

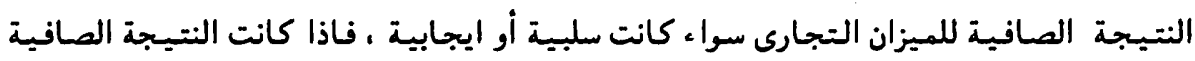

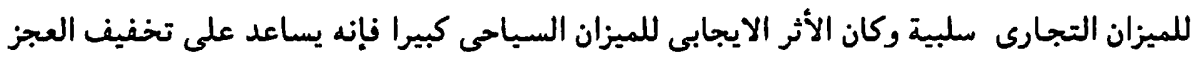

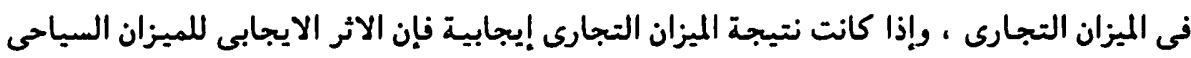

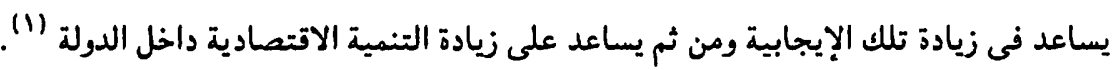
ومصر بصفتها إحدى الدول السياحية النامية التى تعانى من عجز فى العملات الأجنبية نتيجة

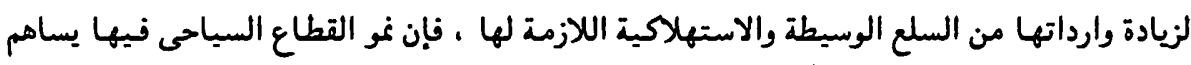

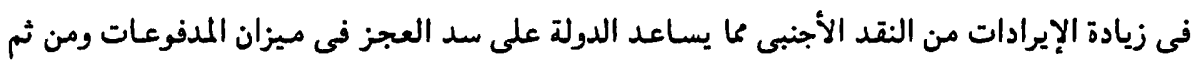

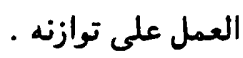

ويبين لنا الجدول رقم (1) أثر القطاع السياحى على ميزان المدفوعات.

$$
\text { ومن الجدول يتضح ما يلى :- }
$$

أ - تزايد الأهمية النسبيه لقطاع السياحة بالنسبة للمتحصلات الجارية (الصادرات - الملاحه

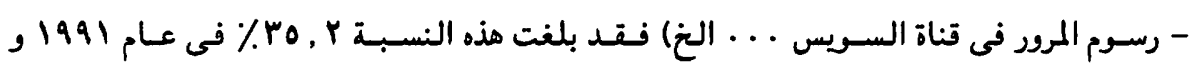
199ع 199. 9 ب - تزايد الأهمية النسبية لقطاع السياحة بالنسبة للصادرات غير المنظورة فقد ارتفعت هذه

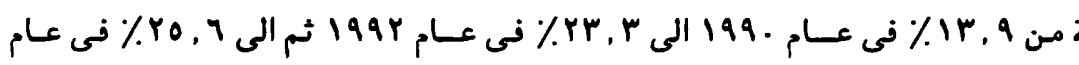
النس

جـ - تزايد الأهمية النسبيـة لقطاع السياحة بالنسبة للواردات فـقد ارتفعت هذه النسبة من

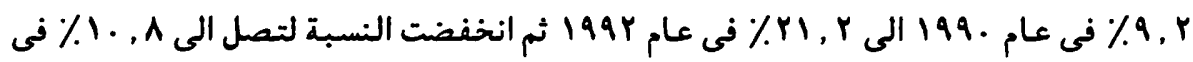

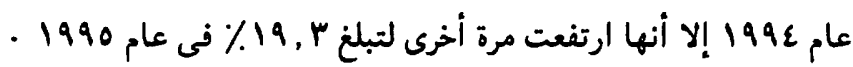


د - وأخيرا يوضح الجدول الأهمية النسبية لقطاع السياحة بالنسبة للناتج القومى الإجمالى

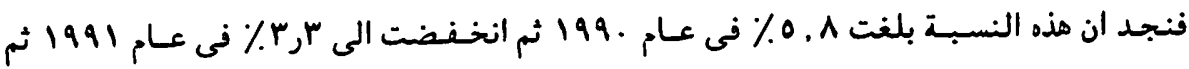

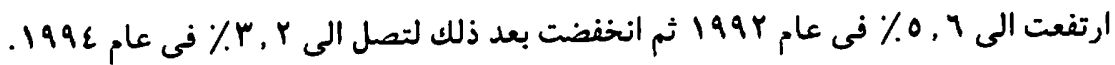

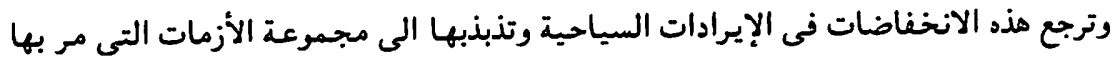
قطاع السياحة فى مصر.

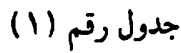

أثر القطاع السياحى على ميزان المدفوعات (r)

\begin{tabular}{|c|c|c|c|c|c|c|c|c|c|}
\hline$\% 0: 1$ & $\% \varepsilon: 1$ & $\% r: 1$ & $\%: 1$ & $\begin{array}{c}\text { القاتج } \\
\text { القومى }\end{array}$ & $\begin{array}{c}\text { الواردات } \\
\text { الوات }\end{array}$ & 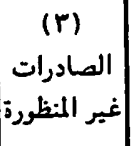 & $\begin{array}{c}\text { (Y) } \\
\text { التحصلات } \\
\text { البارين }\end{array}$ & $\begin{array}{c}\text { الايرادات } \\
\text { السياحبة }\end{array}$ & \\
\hline 0,1 & $q, r$ & $1 r .9$ & $\Lambda_{0}, 0$ & 0.187 .7 & rirar & r.9YI, Y & $r_{\varepsilon} \cdot v, 1$ & arIE, O & 199. \\
\hline$r . r$ & Ir.r & ir.v & ro.r & $|r| . o r$ & rravi, r & rivru. & Irrgo,r & ERYY,o & 1991 \\
\hline 0.1 & MI. r & $r r . r$ & $\varepsilon 9,9$ & irerro & rotur. z & $r r \varepsilon 9 \wedge, 1$ & 10101 & YoYA. I & 1998 \\
\hline$r, r$ & $1 r, \varepsilon$ & 10.7 & $V, r$ & iratry & rOAk., T & rAoll,$\lambda \mid$ & Trq.V & EEVT, T & 1994 \\
\hline$r . r$ & $1 . .1$ & $1 \varepsilon . \varepsilon$ & ryl & $|\varepsilon 7|<9$ & $\varepsilon r(A), V$ & rrelA, Y & 1899.1 & $\varepsilon 79 V, r$ & $199 \varepsilon$ \\
\hline 0.9 & $19 . r$ & ro. 7 & rior.o & lorrya & $\varepsilon 79 r \varepsilon, \varepsilon$ & ror. 1.7 & $\{r), 1$ & 9.71 .0 & 1990 \\
\hline 7.7 & - & - & - & ITYIET & - & - & - & A1. Vo9 & 997 \\
\hline
\end{tabular}

المصدر:

اقتصاديات القطاع السياحى فى مصر وانعكاساتها على الاقتصاد القومى - سلسلة تضايا التخطيط

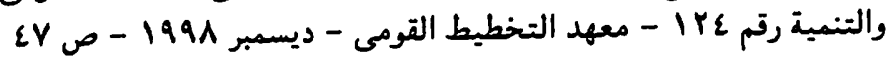

- يتضح من هذا ان تخطيط وتوجيه القطاع السياحى وحسن استغلال الموارد السياحية وتهيئة المناخ المناسب للنمو السياحى وإدارة أزماته بصورة سليمة يساعد على توازن ميزان المدفوعات.

\section{r- السياحة والعمالة :}

تؤثر السباحة تأثيرا إيجابيا مباشرا على زيادة العمالة وخلت فرص عمل جديدة ، وذلك لأن

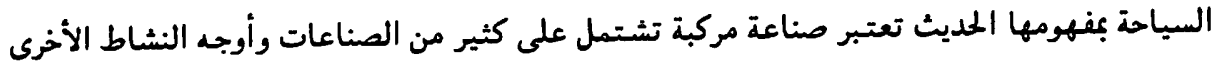

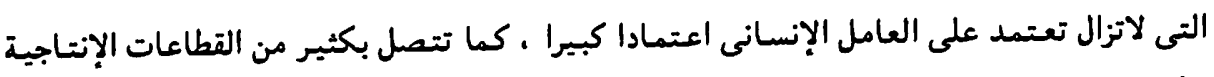

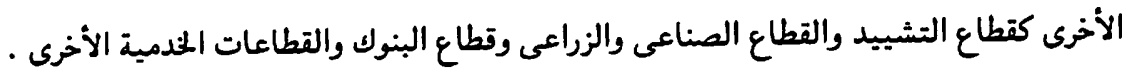
وبين الجدول رقم (Y) حجم العمالة المباشرة فى القطاع السياحى حتى يونيو 1999 


$$
\text { جدول رقم (r) (r) }
$$

العمالة المباشرة فى القطاع السياحى (r)

\begin{tabular}{|c|c|}
\hline حتى يونيو 1994 & 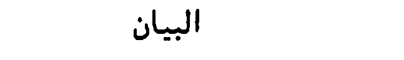 \\
\hline 1178.0 & منشآت الاقامة(الفنادق) \\
\hline$\wedge \varepsilon\rceil \ldots$ & المطاعم \\
\hline$|A| \mid$. & الشركات السياحية \\
\hline$\varepsilon \ldots$. & محال السلع والعاديات السياحية \\
\hline rqso & المرشدون السياحيون \\
\hline ryry.. & الاجمالى \\
\hline
\end{tabular}

تلك هى أرقام العمالة المباشرة فى القطاع السياحى حتى يونيو 1999 ـ أما العمالة غير المباشرة

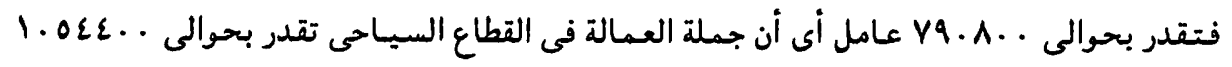

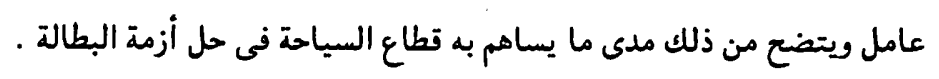
وهناك حقيقة هامة لايكن إغفالها وهى أن خلق فرص عمل جديدة فى القطاع السياحى لايحتاج

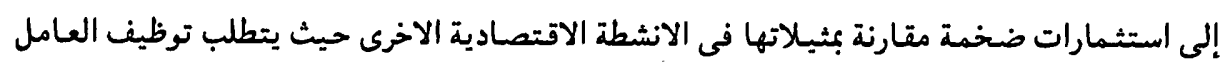

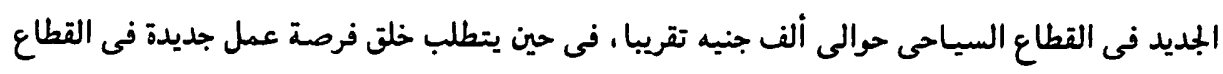

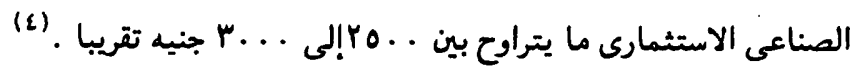

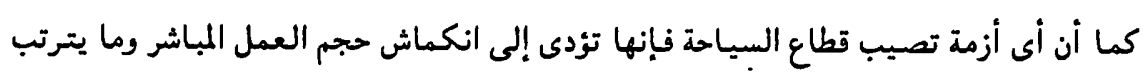

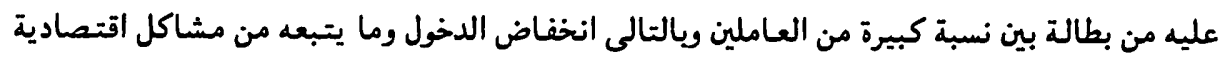
واجتماعية .

وأخيرا يكن القول إن تطور وتنمية القطاع السياحى يكن أن يساعد على توازن هيكل العمالة فى الاقتصاد القومى ·

r - السياحة واعادة توزيع الدخل القومى (o)

تؤدى السياحة إلى تطور وتنمية المناطق الاقل حظا من التنمبة اذ تتجه التنمية السياحية غالبا

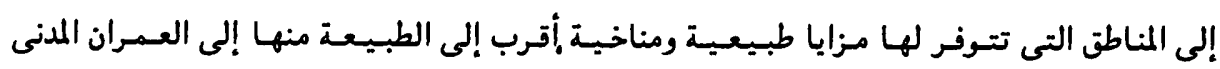


كالشاطىء ومناطق الجبال والبحيرات والتى كثيرا ما تكون محرومة من العمران الذى يصاحب التقدم

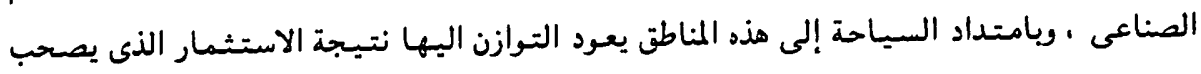

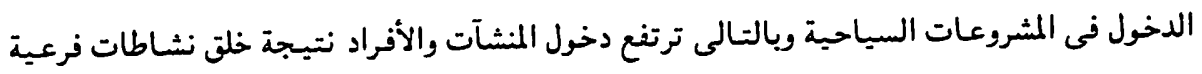

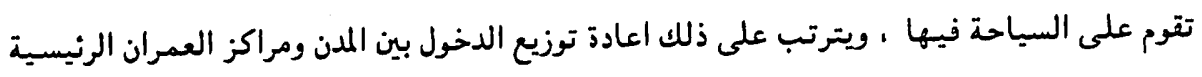

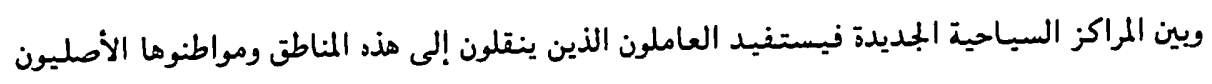

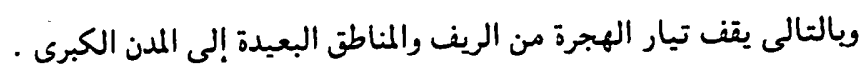
ع - السياحة والمستوى العام للأسعار : تزيد السياحة من الانتاج والاستهلاك كغيرها من القطاعات الانتاجية وبذلك تيل الأسعار إلى الى الارتفاع بسبب ارتفاع مستوى المعيشة .

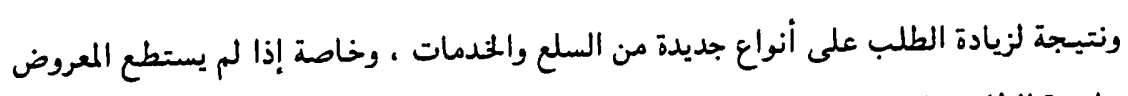

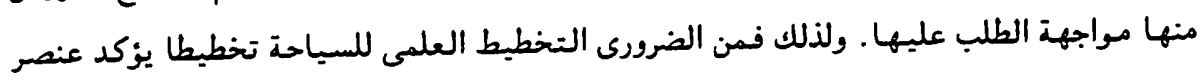

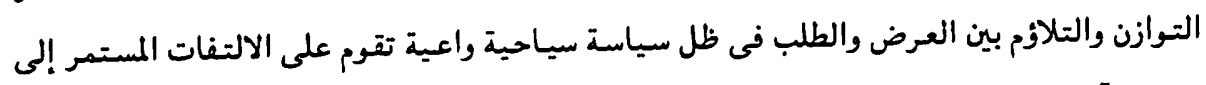

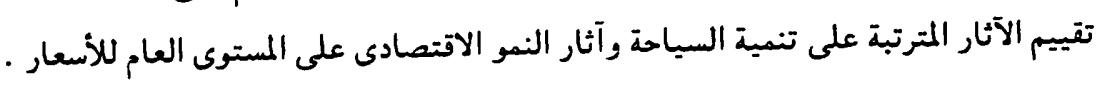

\section{الآثار غير المباشرة لقطاع السياحة

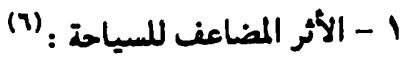

لاتقتصر الآثار الاقتصادية للدخل السياحى على حصيلة هذا الدخل بل تتعداها إلى مضاعفات

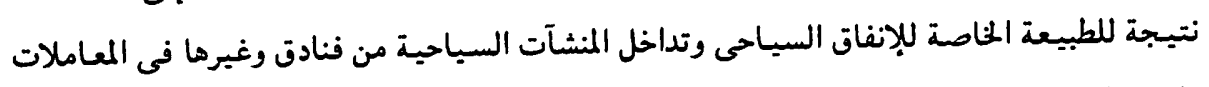

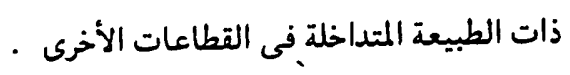

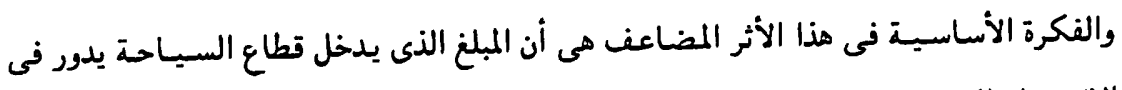

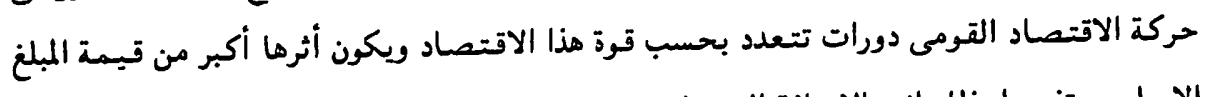

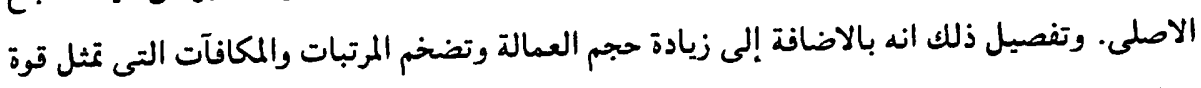

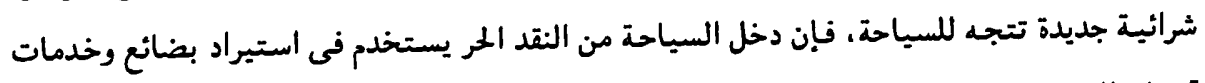

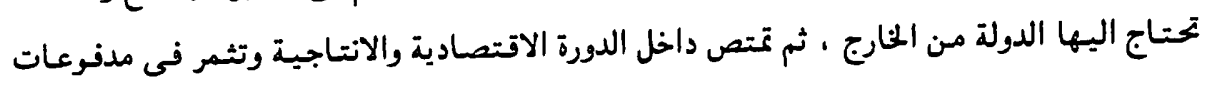

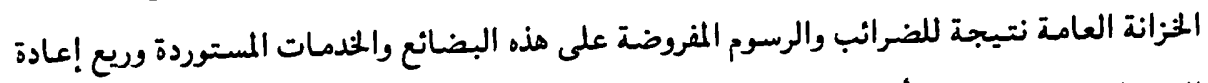

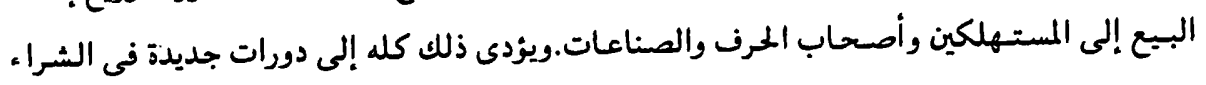


والانفات داخل الدولة.

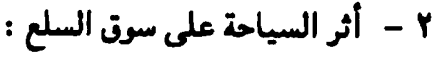

تبين من الدراسات الحديثة أن السائحين يحتفظون بحوالى ثلث ميزانياتهـم الترويحية للإنفاق على المثتريات من الدولة التى يزورونها مثل التذكارات السياحية والمنتجات الوطنية دون حاجــة إلى شحن ومجهودات تسويقية خارجية ويالتالى يعتبر هذا تصديرا خالصا من المنافسة الدولية وكلما زادت حركة السياحة ارتفعت حصيلة هذا التصدير من داخل الدولة إلى المشتـرين والزائرين، كما تبين

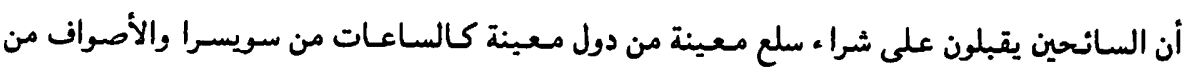

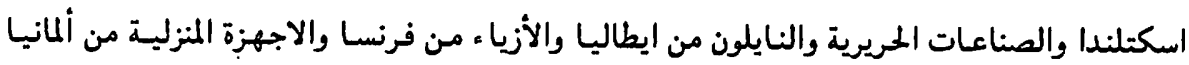
والدول الاسكندنافية والسجاد والمنسوجات اليدوية من إيران وتركيا وأفغانستان والهند. وقـد لوحظ فى السنوات الحمس عشـرة الاخـــرة اقبـال السـائحين القـادمين لمصر على شـراء منتجات خان الخليلى ( الجلدية والمعدنيـة والخشبية المطعمة بالصدف ) ومن الجمدير بالذكر أنه يجب توجيه الاهتمام إلى هذا الجانب من اقتصاديات السياحة وتوسيع دائرة المنتجات اليدوية المصرية .

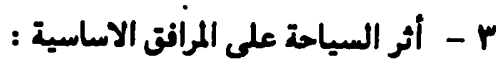

ويظهر هذا الاثر بوضوح فى الدول النامية التى لم تصل فيـها المرافق الاسـاسية العـامة إلى حجمها المناسب وذلك لانخفاض مستوى المعيشة ففضلا عن المرافق الاساسية من مطارات وموانى سياحيـة وتطور عمرانى للمناطق الرئيسية للجذب السياحى داخل الدولة ـ فان السياحة وزيادة الحركة السياحية بصورة منتظمة وما يترتب على ذلك من دخل سريع بالعملات الحرة يزيد من قدرة الدولة على تحسـين كفا عة مرافقها الأساسية وامتداد العمران السياحى إلى مناطق بعيدة مما يسـاهم فى التنمية وارتفاع مستوى معيشة المواطنين .

\section{ع - مسامة السياحة فى زيادة جذب الاستثمار الأجنبى والوطنى :}

تعتبر المشروعات السياحية من أكثر المشروعات الإنتاجية جذبا لرؤوس أموال المستــــرين الأجانب والوطنيين لأن السياحة كصناعة مركبة تتضمن مجالات مختحلفة للاستبـار مثل المطاعم والملاهى ومراكز الرياضة والترويح والقرى السياحية والبواخر السياحية وشركات السياحة وركالات 
السفر ووسائل النقل السياحى بالاضافة إلى المشروعات الكبرى مثل تخطيط مدن سياحية متكاملة. كما يؤدى دخول الاستثمارات الأجنبية إلى خبرة المستــمرين الوطنيين نتيجة اختلاطهم بالمستـمرين الأجانب من ذوى الخبرات الأكثر تقدما عا يدفعهم إلى الأخذ بأسباب التطور التكنولوجى والبحث العلهى ، كما تؤثر أزمات السياحة تأثيرا سلبيا فى جذب الاستثمارات حيث يترتب على حدوث أى أزمة إحجام معظم المستثمرين عن الاستثمار فى قطاع السياحة .

ويوضح لنا الجلدول رقم( r ) تطور الاستــمـارات فى القطاع السـياحى خلال الفتـرة من عام

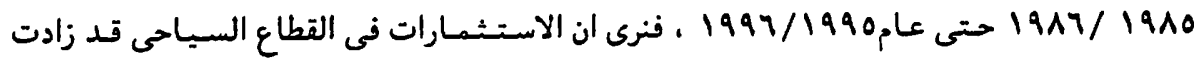

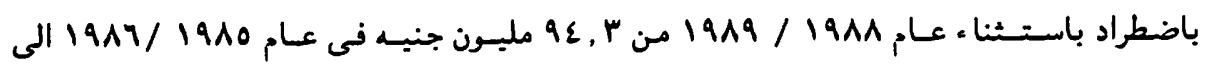

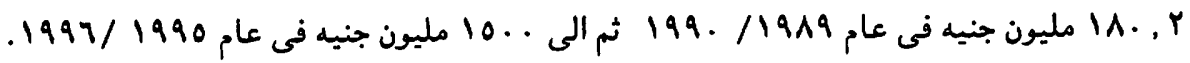
وعلى الرغم من تذبذب قيمة الاستثمارات فى القطاع السياحى الى اجمالى الاستثمارات فانها

$$
\text { جدول رقم (r) }
$$

تطور الاستتمارات فى القطاع السياحى خلال الفترة من

عام 19197/1910 حتى عام 1997/1990

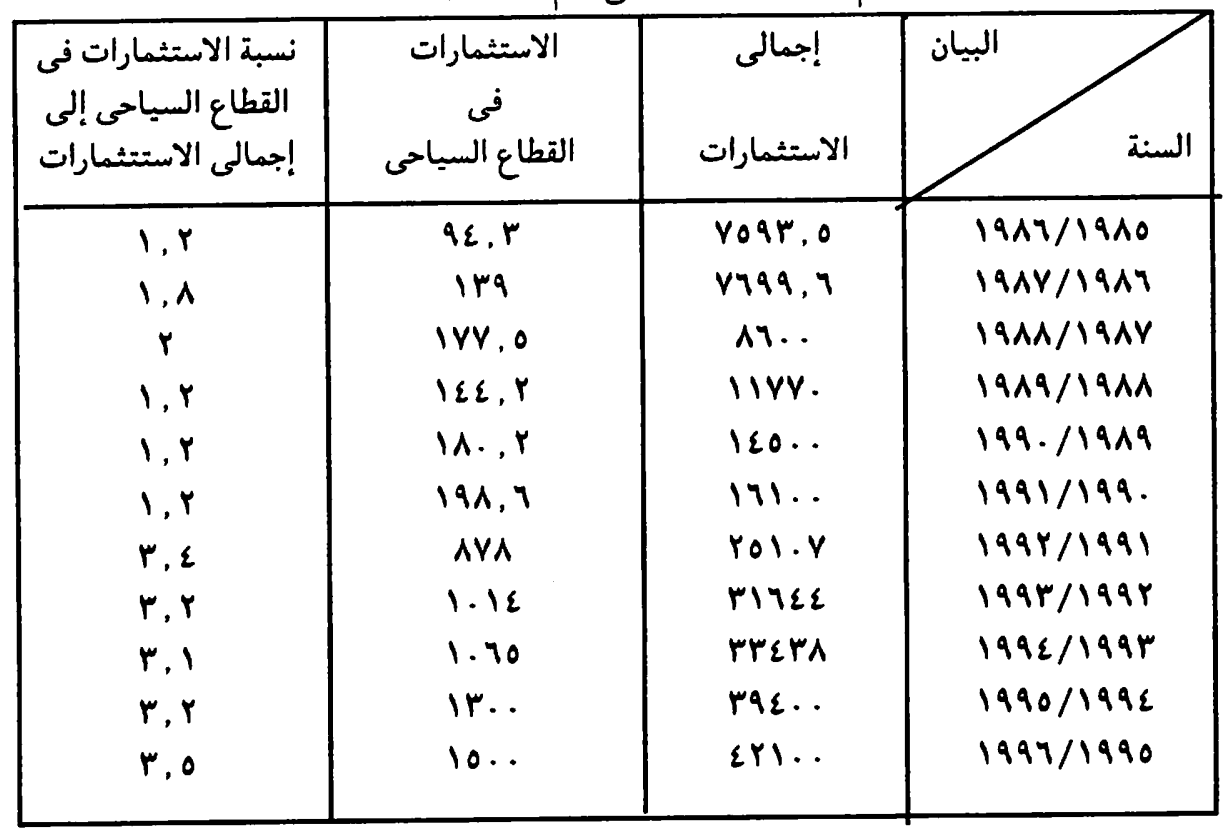




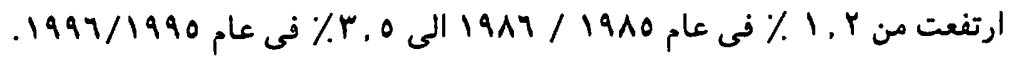

ومن دراسة الأهميـة الاقتصادية والاجتماعية لقطاع السياحة نتوصل لنتيجة هامة وهى أن قطاع السياحة يكون مع بقية القطاعات الأخرى فى الدول حلقة مغلقة يكن أن نطلق عليها ما يعرف باسم حلقة تغذية عكسية ويكن تمثيل هذه الملقة كما في شكل رقم (r) . فالزيادة في عدد السـيـاح والليالى السيـاحيـة ستـؤدى حتما إلى زيادة الاقبـال على استهالك المتـجات الزراعية والصناعية وأيضا زيادة فى المنشآت السياحية التى تحــاج إلى أيدى عاملة كما ستؤدى إلى خلق مناطق جذب سياحية جديدة وما يتبعها من إنشاءات فندقية وقرى سياحية وغيرها عا يتطلب شبكات جديدة من الطرت والمواصلات وهكذا بالنسبة لبقية أنشطة الدرلة الاقتصادية .

(r) شكل حلقة تغذية عكسية بين الزيادة فى قطاع السياحة والقطاعات الأخرى

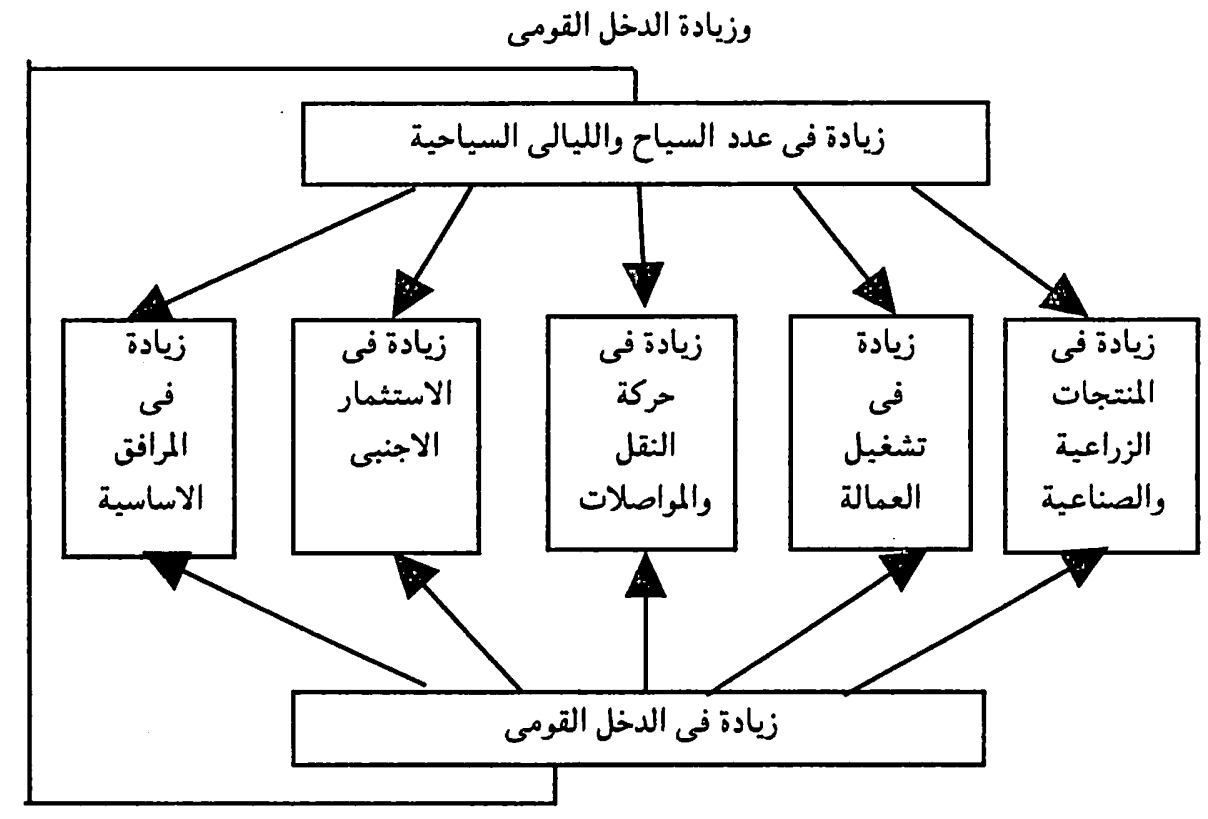

المصلر : (من إعداد الباحثة) 


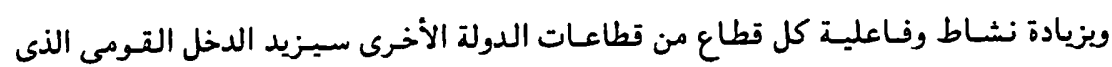

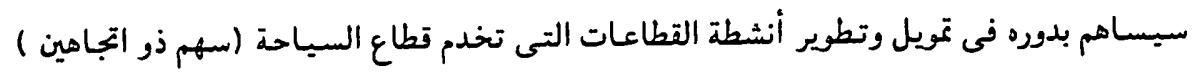

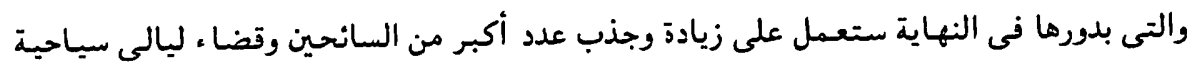
أطول وهكذا.

ولكى تؤدى هذه الحلقة دورها بنجاح ويعظم الفائدة منها ، فإنه يجب أن تعمل جميع مكونات

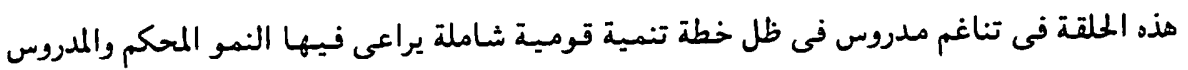

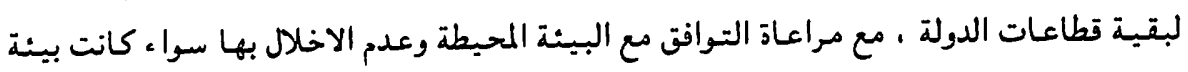

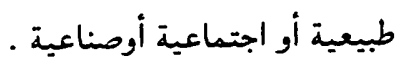

ثانيا : العلاحات التأثيرية المتبادلة بين السياحة والبينة :

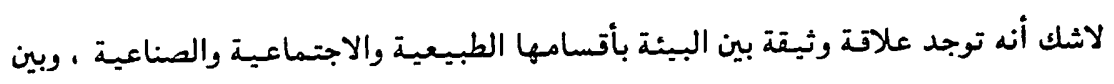

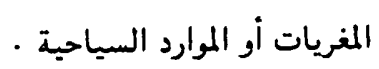
فالسياحة تمثل أساسا حركة انتقال الإنسان لتحقيق أهداف منزهة عن العمل أو الكسب الملادى

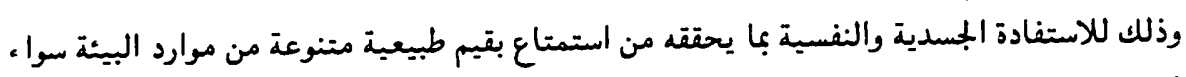
أكانت بيئة طبيعية أو اجتماعية أو صناعية ، والتى تشكل فى مجسموعها مختلف الاقسام المكونة

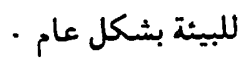

ومعنى ذلل ايضا أن كل مايؤثر على البيئة بأقسامها المختلفة سواء بالسلب أو الايجاب

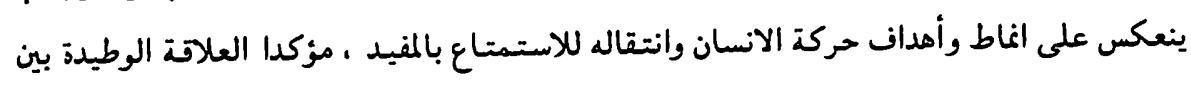
البيئة الطبيعية و الاجتماعية والصناعية ويين الموارد السياحية . ويتناول هذا الجزء من الدراسة الأبعاد الفكرية لمفهوم البيئة ثم مقارنة بين تقسيمات البينة

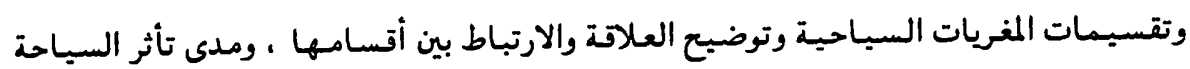

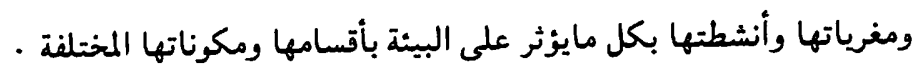

\section{الأبعاد الفكرية لمفهوم البيئة}

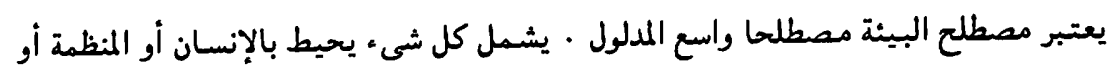

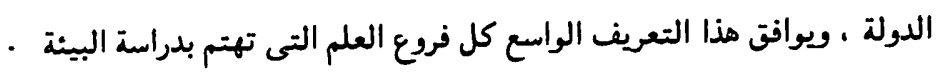


وفى مضمون أكثر تحديدا عرف مؤتمر الأمم المتحدة للبيئة الذى عقد فى استوكهولم عام I9YY

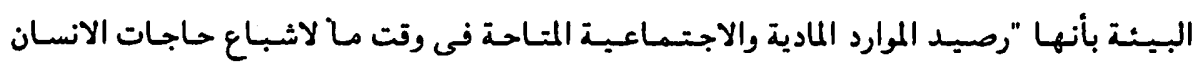

وتطلعاته". (A)

كما عرنت البيئة أيضا بأنها مجموعة الظروف والعوامل المارجية التى تعيش فبها الكائنات

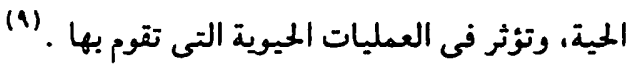

وفى تعريف أكثر شمرلية يرى القصاص أن المجتمعات الانسانية تعبش فى اطار منظومات

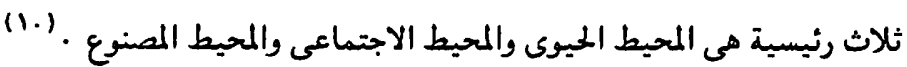

أ - المحيط الحيوى : هو ذلك النطاق من كوكب الارض الذى توجد به الحياة فى أحد صورها

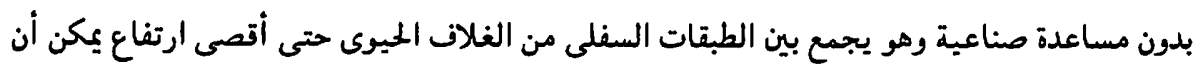

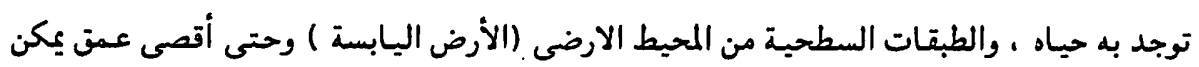

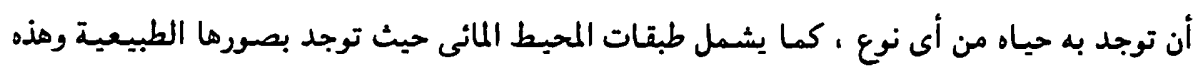

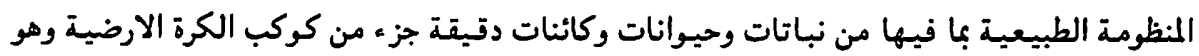

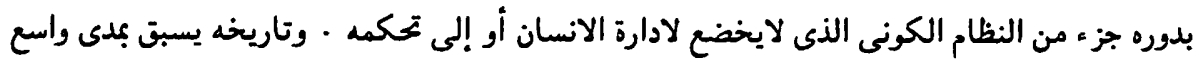

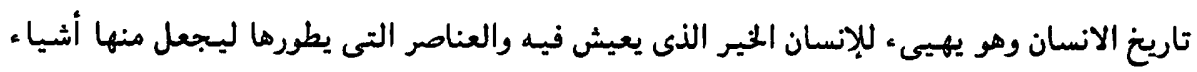

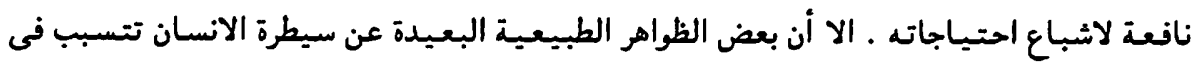

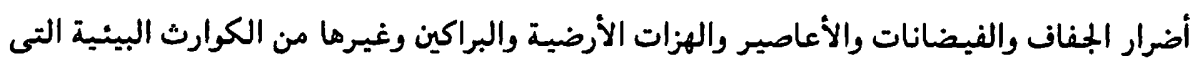

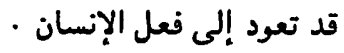

ب - المحيط المصنوع : وهو يتمثل فى كل ما صنعه الانسـان ويناه وأتـامه فى حيـز المحيط الميبوى من مساكن ، ومراكز صناعية ، وشبكات مواصلات وشبكات رى وصرف ومراكز الطاقة

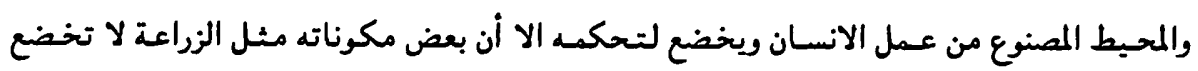

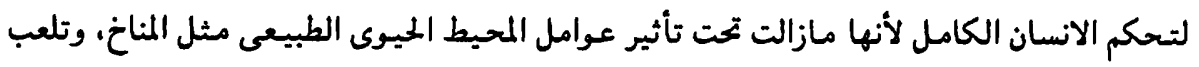

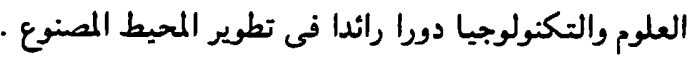
جـ - المحيط الاجتماعى : وهى مجمموعة النظم الاقتصادية والأعراف الاجتماعية والأدوات الإدارية والتشريعية والمؤسسات التى ينتظم فى إطارها دولاب حياة الجماعة الانسانية وهى المنظومة 
التى تدير فى إطارها الجماعة الانسانية شُنون حياتها الاجتماعية والاتتصادية .

ومن منطلق هذه المفاهيم نستنتج أن البينة ذات ثلاثة نظم هى النطام الطبيعى : وهو مايعرف بالبيئة الطبيعية ويشـمل كل مظاهر الوجرد المحيط بالانسان أى الأرض والما ، والفضا ؛ وما يتواجد بالغلاف الجوى المحيط بالأرض من كائنات كالطيور والبكتريا وغيرها .والثانى هو النطام الصنوع . ويشـــل : كل مـا صنعـه الإنسـان وشـيـده على سطح الأرض من حضـارة مصنوعـة بكل مكوناتها البنائية. أما الثالث فهو النظام الاجتماعى : أى البيئة الاجتماعية وتشمل النظم والعلاقات التي

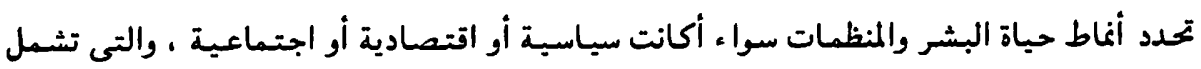

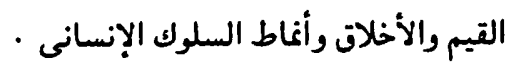

والمنظومات الثلاث بمكوناتها الطبيعية والمصنوعة والاجتماعية يتشكل منها العديد من الموارد والمغريات السياحية أى العرض السياحى والذى يرتبط بعديد من الأناط السياحية التى يتشكل منها الطلب السياحى كما يتبين تفصيليا من العرض التالى والذى يوضح العلاقة بين موارد البينة ويين المغريات أو الموارد السياحية المئ

\section{r- العلاحة بين موارد البيثة بين المغريات أو الموارد السياحية :}

تتضع العلاقة بين موارد البيئة وموارد السياحة من المقارنة الموضحة بالتقسيمات التالية والتى تتعرض لتقسيمات البيئة وتقسيميات المغريات السياحية باستخدام منظومات البينة السابق ذكرها (الطبيعية والاجتماعية والصناعية ) وبين مايقابلها من التقسيم المتعارف عليه من الموارد السياحية

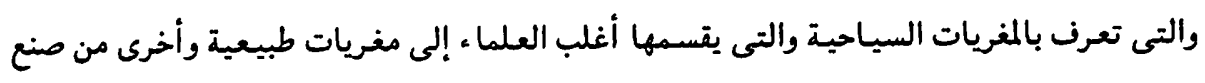
الإنسان ، مع الإشارة إلى ما يقابل هذه المغريات من الأنشطة السياحية والأنماط المتعارف عليها وهذا

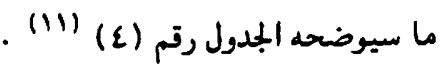

وتشير المقارنة الموضحة سابقا بين أقسام البيئة المختلفة وبين أقسام المغريات السياحية أنه يوجد تاثلل وشبه تطابق بالنسبة للشكل العام لكل من العناصر المكونة للبيـة الطبيعية والاجتماعية والصناعية وعناصر المغريات السياحية كجز ، لاينفصل ولايتجزأ عن عناصر البينة وذلك بالرغم من الاختلاف الموجود فى الثـكل التنظيمى والمسميات التى تقتضيها المناهج والمفاهيم العلمية لكل من علم السياحة وعلم البيئة . 
جدول رقم (ع)

تقسيمات البيئة وتقسيمات السياحة

\begin{tabular}{|c|c|c|}
\hline الأنثطة السياحية السياحة) & (المغريات السياحية) & (المنظومات البيئية) \\
\hline 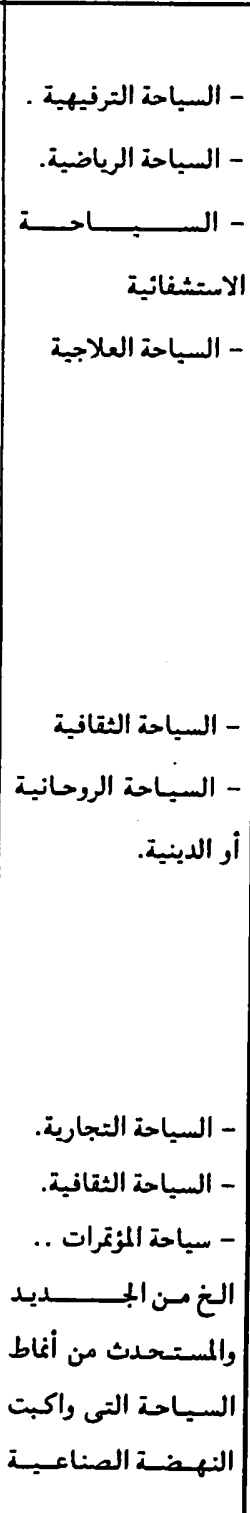 & 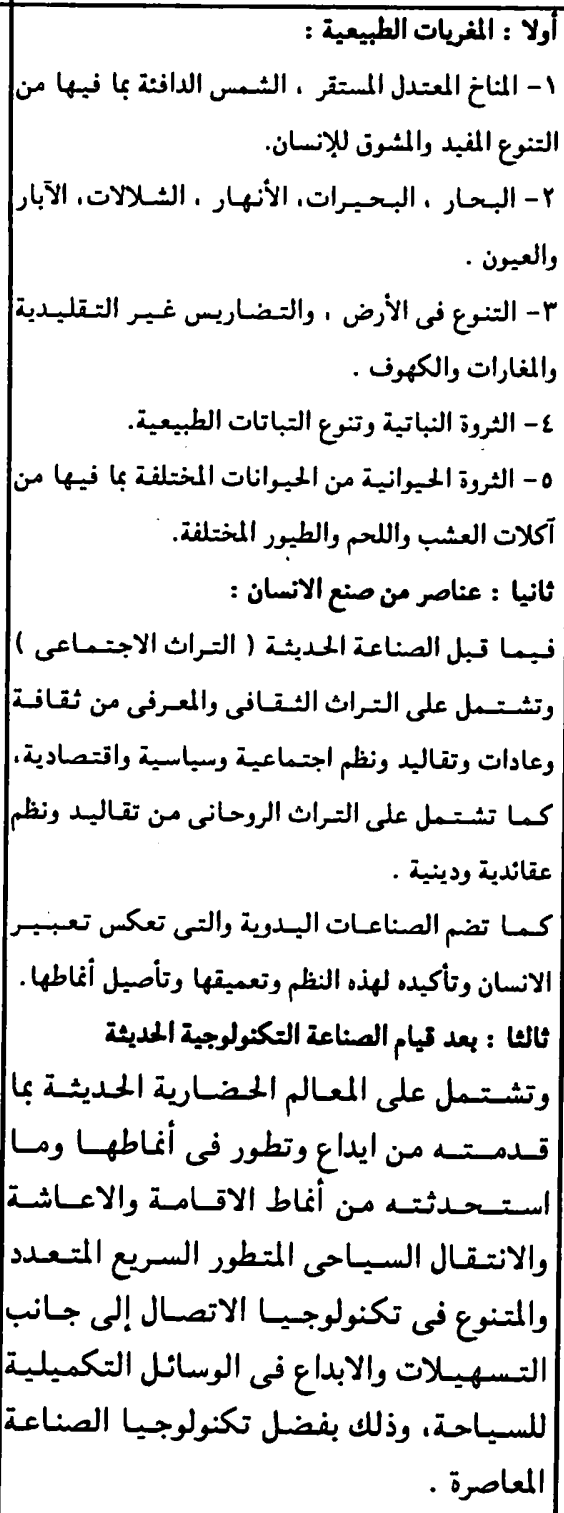 & 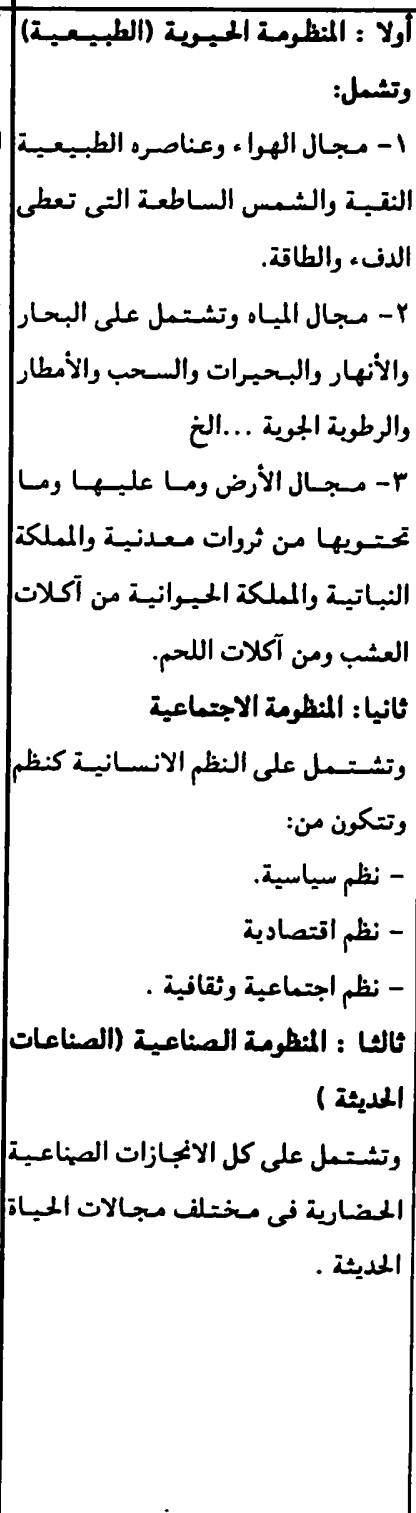 \\
\hline
\end{tabular}


ولمعرفة طبيعة العلاقة بين البيئة والسياحة، فان هذا التقسيم يحتاج إلى مزيد من التعمق

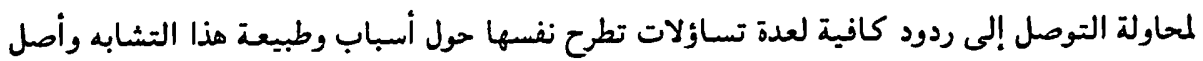

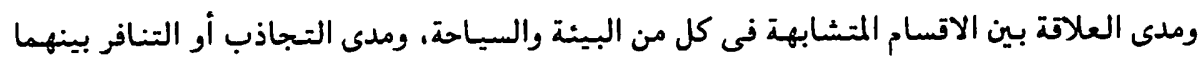

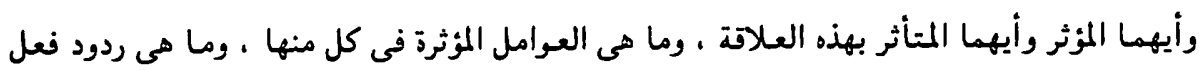
هذه العوامل على العلاقة بينهما .. الخ من هذه التساولات التى تؤدى الاجابات عليها إلى توضيح التهيح وتحديد وتدعيم وتأصيل للعلاقة بين البيئة والسياحة .

وكمحاولة لإجراء تغطية شاملة للاجابة عن التساؤلات المطروحة حول طبيعة العلاقة بين موارد البيئة وموارد أومغريات السياحة ، فإنه يمكن تضمين الاجابات المطلوية لهذه التساؤلات من خلال

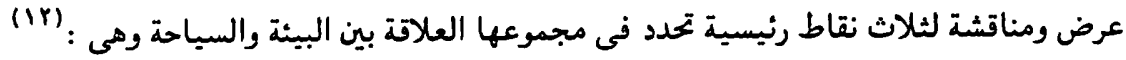
- طبيعة العلاقة بين عناصر البيئة الطبيعية بالمغريات السياحية الطبيعية . - طبيعة العلاقة بين عناصر البيئة الطبيعية والاجتماعية والمغريات السياحية الاجتماعية . - مناقشة وضع موارد البيئة الطبيعية من حبث علاقتهبا بالمغريات المصنوعة للسياحة ، ومناقشة أثر التصنيع عليها .

\section{1 - طبيعة العلاقة بين عناصر البيئة الطبيعية والمغريات السياحية الطبيعية :}

لتوضيح العلاقة بين البيئة الطبيعية (المنظومة الطبيعية) والمغريات السياحية الطبيعية ، تجدر

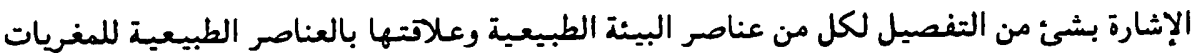

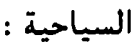

\section{فالبيئة الطبيعية المختلفة أو المجال الحيوى تتكون من :}

- مجال الهواء بما يدور داخله من دورات مستمرة متوازنة لمكوناته من الأكسجين والنتروجين

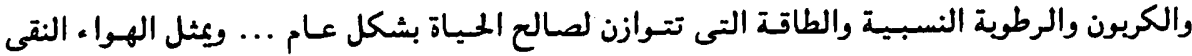

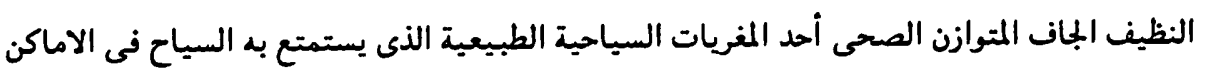

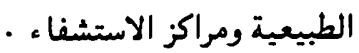
- مـجـال الملاء بما يشــله هذا المجـال من البـحار والانهار والبحـيـرات والينابيع والشـلالات 
والسحب والامطار والآبار على اختلاف مساحتها وأشكال مسطحاتها والتباين فى درجات حرارتها وملوحتها وعذوبتها وما تحتويه من ثروات طبيعية متنوعة من غذا ء وقيم علاجية .. وكنوز وجمال .. .

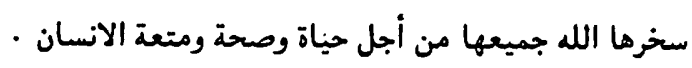
- مجال الارض بما عليها باختلاف أنواعها وارتفاعاتها ووديانها وثرواتها الغذائية وكنوزها الطبيعية بنباتاتها وغاباتها ويراريها وحيواناتها التى لاتعد ولا تحصى سواء فى الأجناس أو الانواع. وتلك المجالات فى مجموعها تتكون منها عناصر البيئة الطبيعية والتى تشكل فى مجموعها

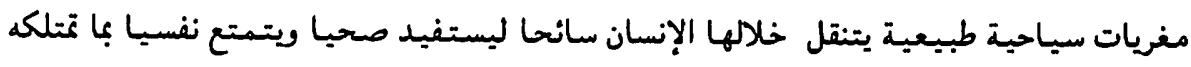

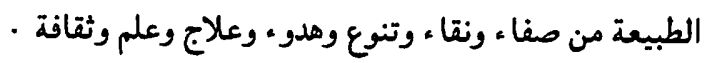

- والانسان ، كعنصر من عناصر البيئة ، يمثل فى المجال الحيوى أرقى الكائنات الحية التى

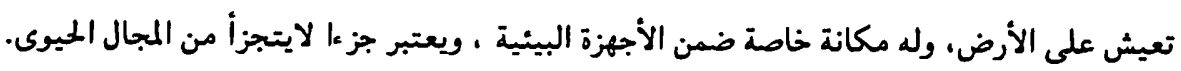
بالاضافة إلى أن وجوده مرتبط بالاجهزة البيئية ويسلامتها نظرا لتطوره الفكرى والنفسى مع

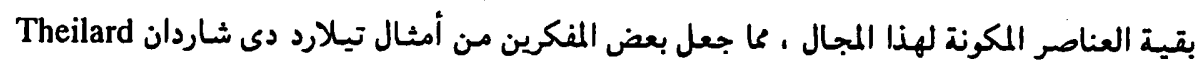
de Chardin

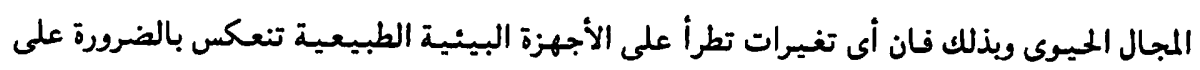
• المجال الفكرى للإنسان

ويعيش الانسان متميزا مع باقى الكائنات الحية بمستوياتها فى المجال الميوى والذى يشكل

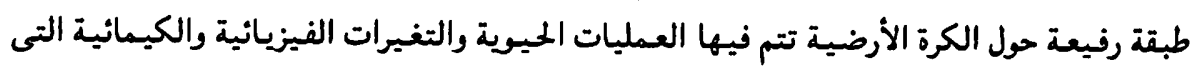

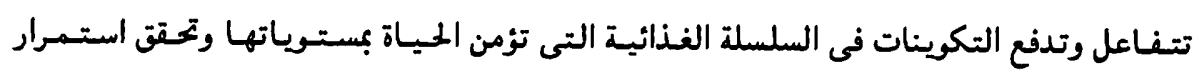

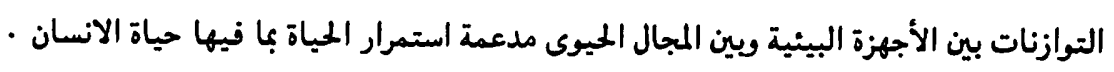

\section{r - طبيعة العلاحة بين عناصر البيتة الطيعية والبئة الاجتماعية والمغريات الاجتماعية السياحية:}

تؤثر البيئة الطبيعبة تأثيرا مباشرا أو غير مباشر فى المجتمع والثقافة ، ففى البيئة الطبيعية

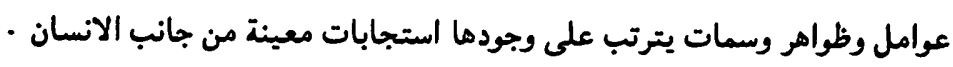
وتتـمثل هذه الاستـجابات فى تكيفات نطية تـفق وطبيعة تلك العوامل البيـيـة من ناحية 
وتوفير حاجات الانسان من ناحية أخرى •

وتلعب البينة الطبيعية دورا كبيرا فى تشكيل المجتمعات من حيث النظم السائدة بين أفرادها والشكل الثقافى والاجتماعى والعادات والتقاليد السائدة فيها ، كما أن دخول التكنولوجيا الحديثة

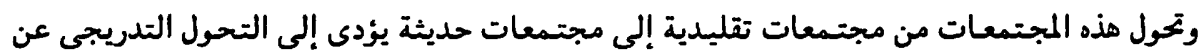

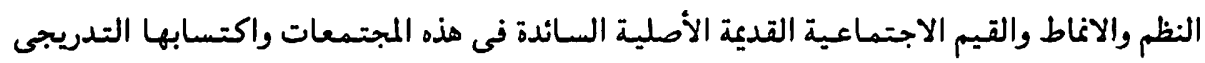

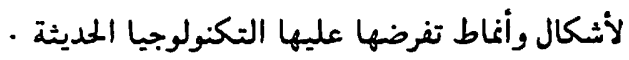
ونظرا لأن التباين فى القيم والعادات والنظم الاجتماعية فى المجتمعات الانسانية التقليدية

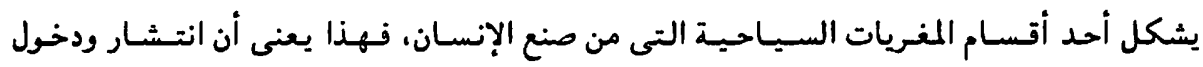

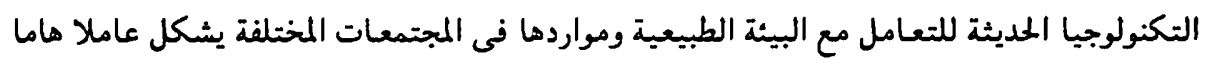

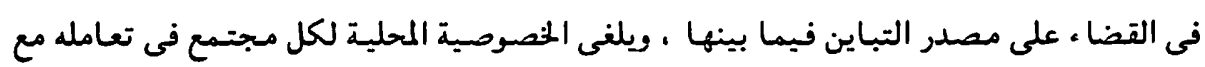

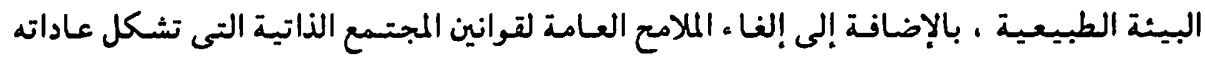
وتقاليده، وفى ذلك قضاء على المغريات السياحية الاجتماعية .

ولايعنى ذلك أن نرحب بالتخلف ومنع التقدم عن المجتـمعات التقليدية أو الناميـة من أجل

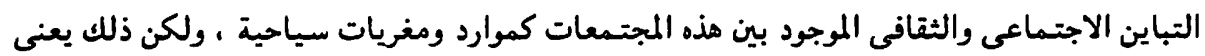

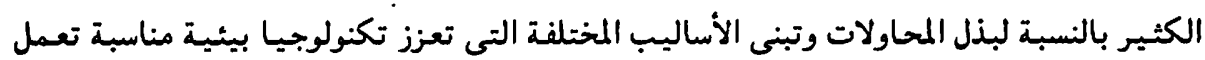

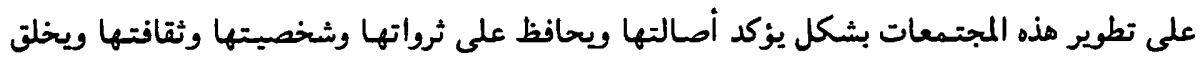

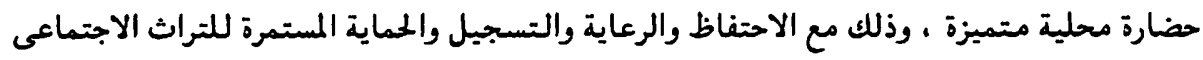

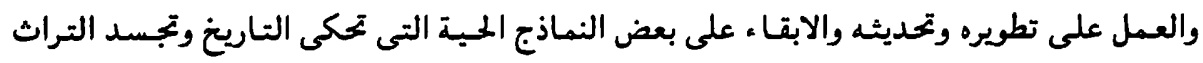

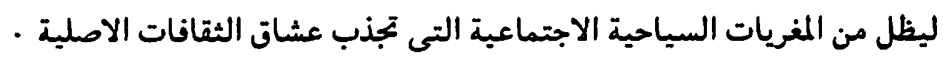

\section{r - طبيعة العلاقة بين موارد البينة الطبيعية والموارد أو المغريات السياحية الصناعية :}

وضحت طبيعة العلاقة بين موارد البيئة الطبيعية والمغريات السياحية الطبيعية أن هذه المغريات

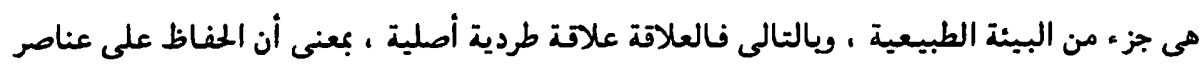

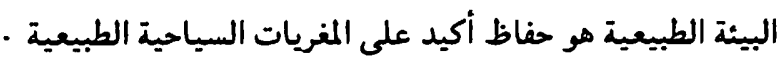

كما أوردت العلاحة بين موارد البينة الطبيعية والمغريات السياحية الاجتماعية أن الموارد 
الطبيعية عتلك البد العليا في نسج وتشكيل الموارد السباحية والاجتماعية دون أدنى فعل أو تأثير

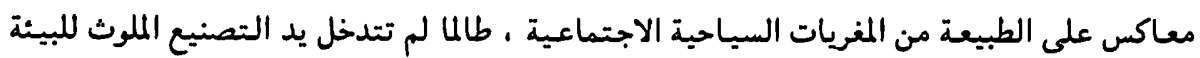

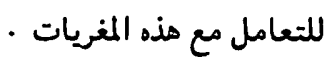

ومعنى ذلل أن العلاقة بين البيئة الطبيعية والمغريات السياحية الطبيعية والاجتماعية تتخذ شكل العلاقة الايجابية الطردية .

ولكن طبيعة العلاقة بين موارد البيئة الطبيعية والمغريات السياحية الصناعية المديثة تتخذ المئل

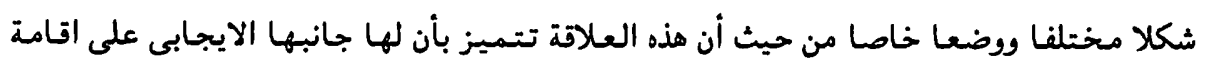

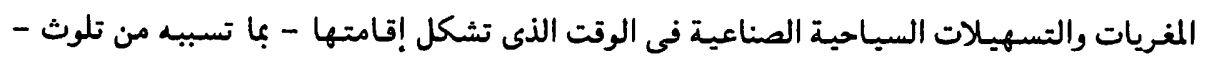
جانبا سلبيا بالنسبة لموارد البيئة الطبيعية .

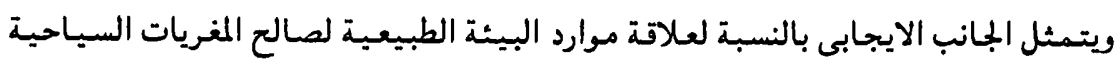

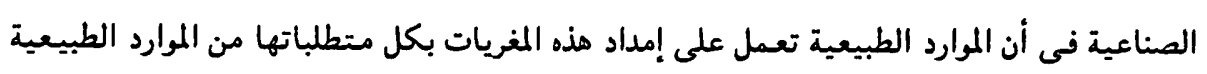

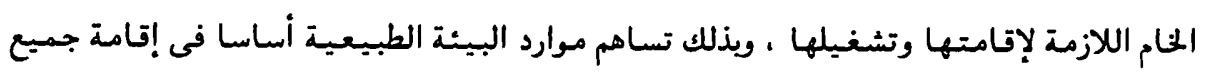

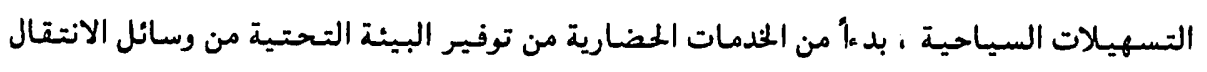

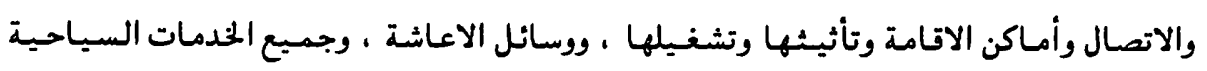

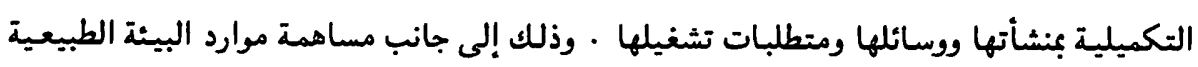

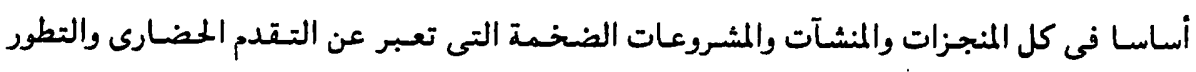
التكنولوجى والذى يشكل فى النهاية مغريات سياحية صناعبة .

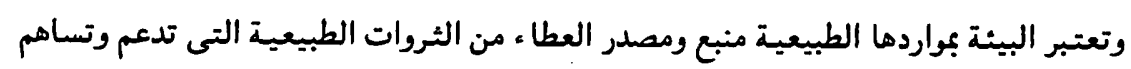

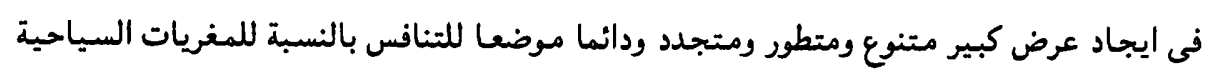

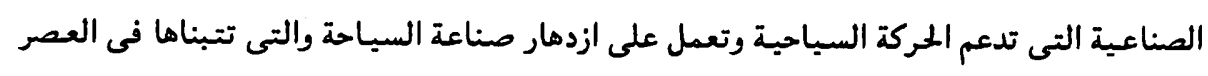

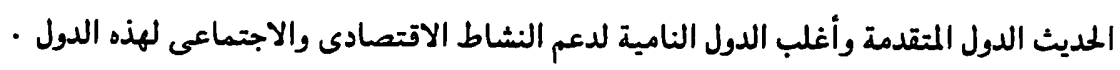

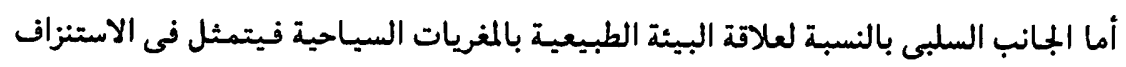

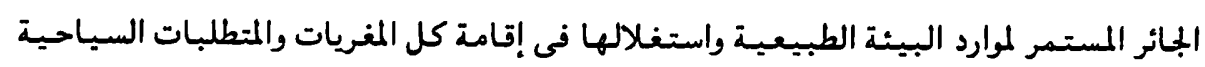

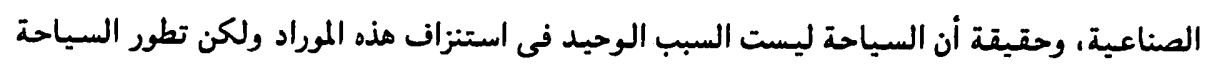


واعتبـارها من اهم الصناعات الاتتـاجية المعاصرة فى معظم الدول يزيد العبء على الموارد البيـيـية الطبيعية ويعمل على زيادة استنزافها .

كسا أدى استخدام التكنولوجيا المتطورة المصاحبة لمرحلة الصناعة الحديثة الى الاستنزاف الجائر

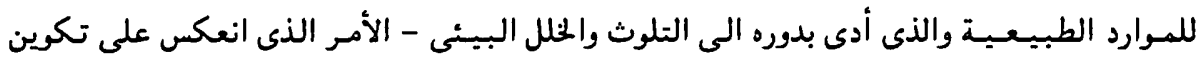

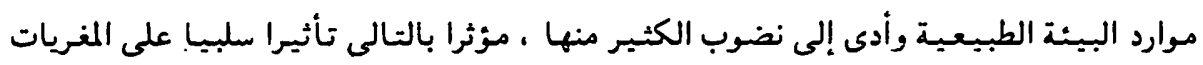
السياحية الطبيعية النمان

\section{ثالثا : يحليل العلاقة بين البيئة والمغريات السياحية}

يشير العرض الذى تم حول العلاقة بين السياحة والبيئة ، والذى شمل توضيح العلاقات بين

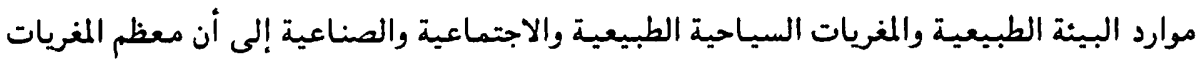

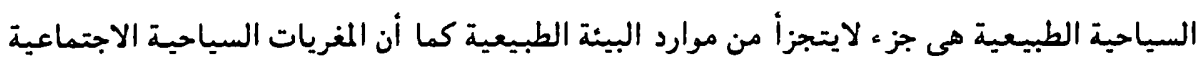

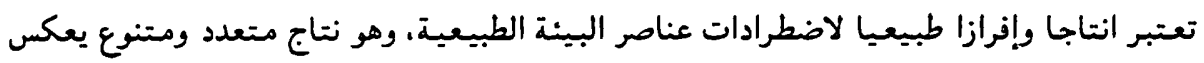

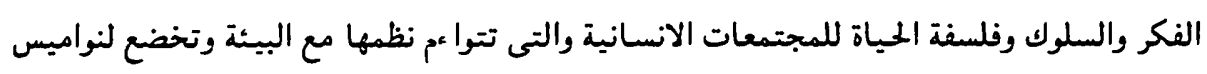
ودستور الطبيعة .

كما أثرت البيئة الطبيعية على طابع المغريات السياحية المصنوعة والتى تيزت فبها مرحلة

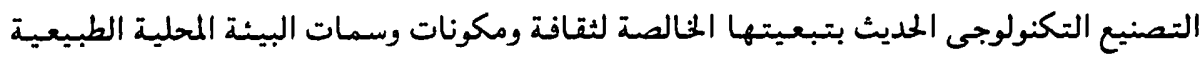

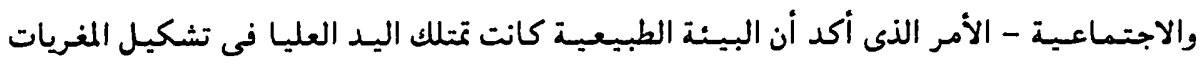

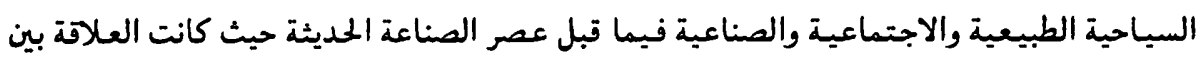

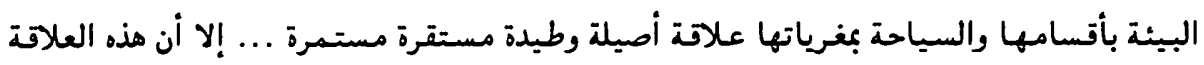

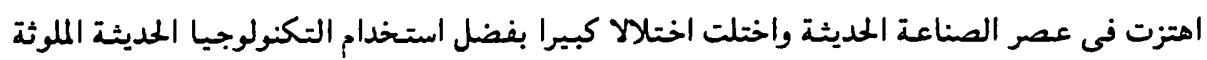

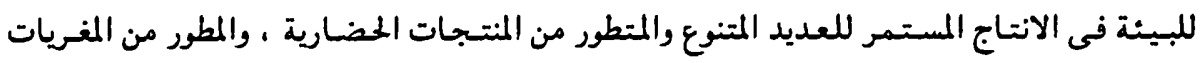
السياحية الصناعية ، مهددة فى ذلك البيئة الطبيعية ومواردها ، والمغريات السياحية وعناصرها

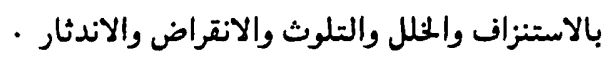

وليس هذا هو التأثير الضار الوحيد لفعل الصناعة بالنسبة للمغريات السياحية الطبيعبة.

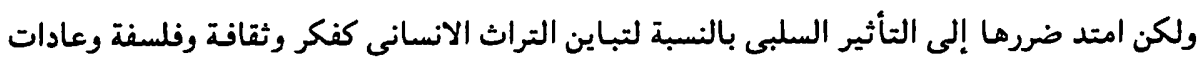


وتقاليد ونظم وأنماط اجتماعية ذاتية محلية ، وذلل بما فرضته الصناعة والتكنولوجيا الحديثة من نظم

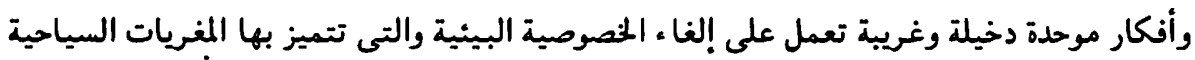

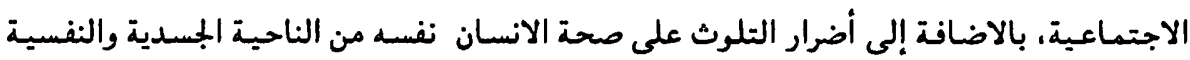

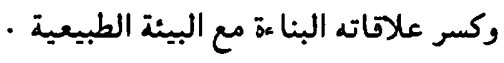

\section{رابعا : الأزمات البيئة وعلاماتها بالسياحة فى ج •م·ع•}

تعتبر البيئة هى العنصر الرئيسى فى تنمية السياحة المتواصلة وهى الشريان الذى تتنفس من

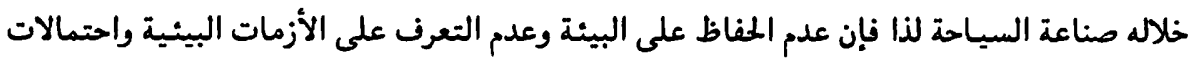

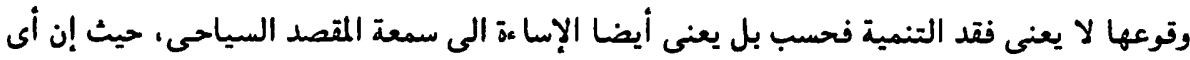

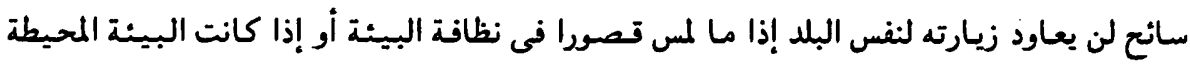
تتعرض للأزمات المختلفه .

ومن هذا المنطلق فإن الأزمات المتنوعة التى تتعرض لها البيـة المحيطة بالقطاع السيـياحى بأنظمتها المختلفة (الطبيعيه والمصنوعة والاجتماعيه) تنعكس انعكاسا ملحوظا على حجم الطلب

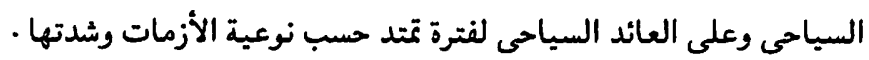

ويكن إجمال الأزمات المؤثرة على الطلب السياحى فى ج ·م·ع فى الزلازل والسيول والأمراض والأوبئة والتلوث بمختلف أنواعه وعدم استقرار الأمن الداخلى وضعف الاستقرار السياسى والدعاية

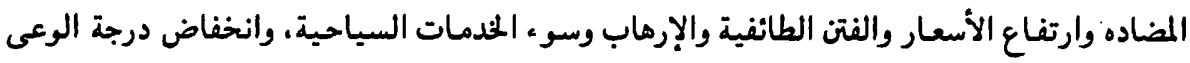
السياحى لدى الشعب ونقص الكوادر البشرية فى مجال السياحة وانخفاض مستوى الملدمة الصحيه. كما تتأثر السياحة بالأزمات السياسية والدعاية المضادة للدولة.

ولقد أوضحت الإحصاءات فى هذا الصدد فى إحدى الدراسات التى قامت بها الباحثة لقياس

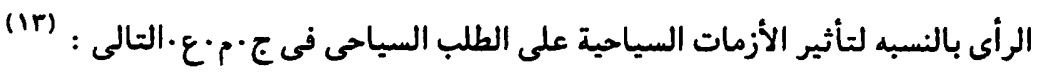
(1) تمثل المشاكل السياسية بمنطقة الشرق الأوسط أكبر نسبه تأثير على السياحة حيث تصل

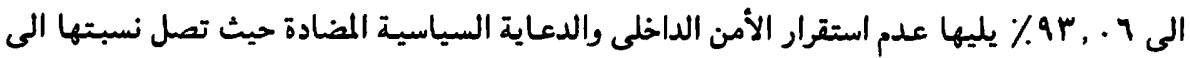

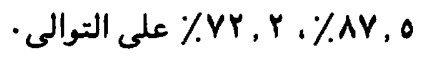


(Y)

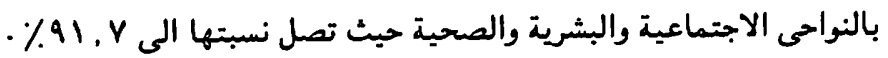
(r) ترتفع نسبة الأزمات المتـولدة من البيئة الطبيعبة فقد أوضحت الدراسة وصول تأثير

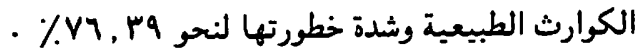

وبالنظر الى هذه النتائج يصبح من المحتم دراسة تلك الأزمات التى يمر بها قطاع السياحة فى أنى

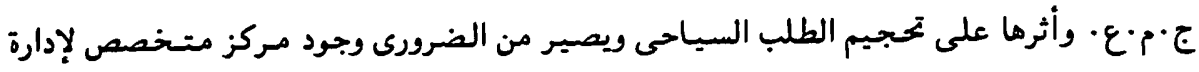

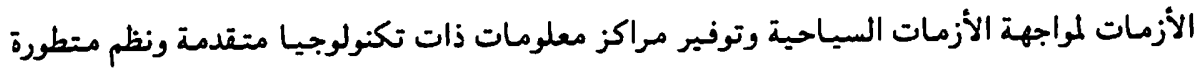
للاتصالات مع العمل على وجود كوادر قيادية مدربه ذات قدرة على الاستيعاب والتحليل والتيل والتقييم والتنبؤ بالأزمات وكشف أوجه القصور وعلاجها .

\section{خامسا : التنعية السياحية المتواصلة (المستدامه)}

يككن القول إنه فى سبيل تحقيق تنميه سياحية حقيقية لابد من استخدام مفهوم التنمية

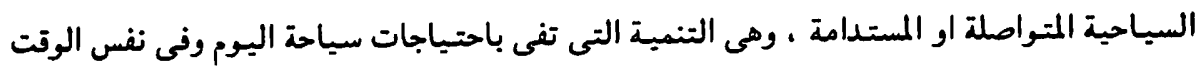

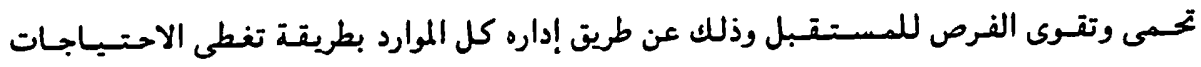
الاتتصادية والاجتماعية مع عدم الإخلال بالبيئة أو بالموارد البيئية . (Iع) : ولعل من أهم أهداف التنمية السياحية المتواصله مايلى (1) تنـيـة لاتدمر ولاتضر بالبيـنة وتحافظ على الاطار الايكولوجى وتتفادى الآثار الضارة

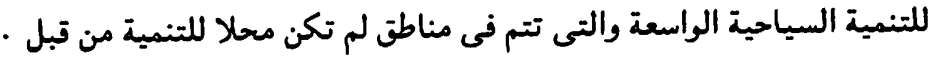
(Y) اقامة مشروعات تنمية صغيرة متعددة أو عناصر جذب سياحية تقيمها المجتمعات المحلية بحيث تكون مقبوله لدى المواطنين المحليين .

لابد أن إسافي التركيز على الاستمرار الحضارى والاجتماعى فالسياحة لايمكن أن تدمر البيئة الاجتماعية

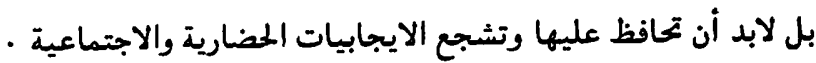

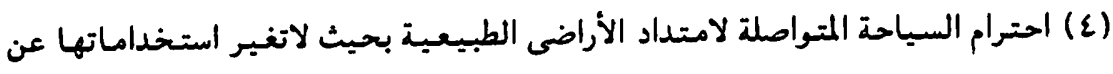

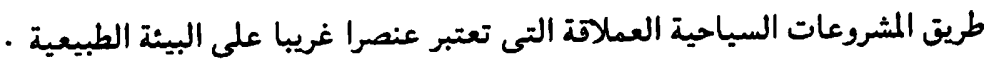


واخيرا فإن التنمية السياحية المتواصلة هى الوسيلة الفعالة لحسن إدارة الموراد البيئية والبشرية

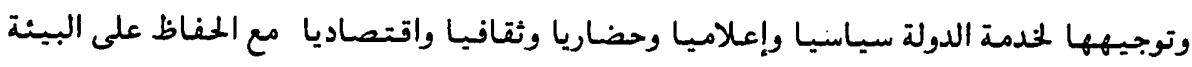
بأقسامها المختلفة وحمايتها .

\section{سادسا : أهمية الوعى البينى كمدخل للتنمية السياحية}

يرتبط نجاح أهداف التنمية السياحية ارتباطا كبيرا بدى الوعى والإدراك وإحساس الإنسان

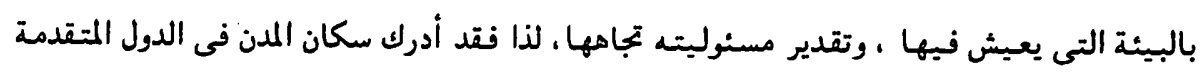

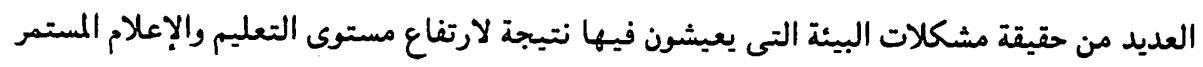

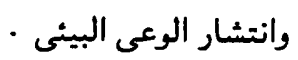

ويذلك ارتبطت ظاهرة السياحة للإنسان المتحضر ارتباطا جوهريا برغبته فى حماية وتدعبم

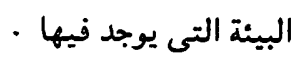
ومن ناحية أخرى فان الوعى والتثقيف البينى يعتبر المحرك الاساسى فى انتقال الانسان من

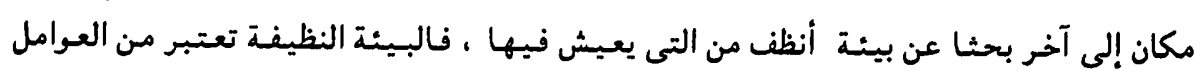

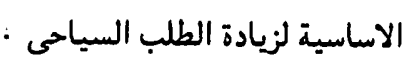

ويعتبر زيادة الوعى والتثقيف البينى من أهم الأشيا ، التى يجب أن تحرص عليها الدول النامية

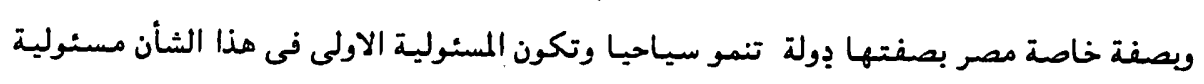
وسائل الإعلام المختلفة (المسموعة و المقروءة والمرئية) فهى الأساس فى توعية المواطنين بأهمبة البيئة

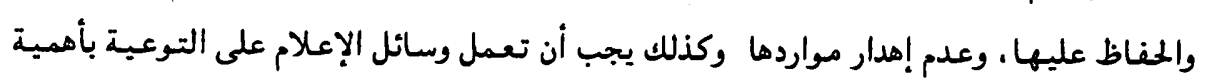

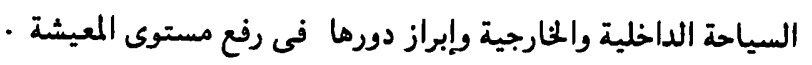
ومن الضرورى بكان أن تركز وسائل الإعلام على الضمير البينى الذى ينبع من داخل الإنسان.

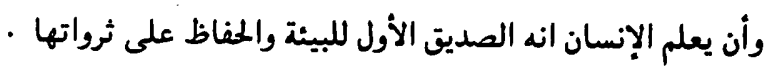




\section{الحاتمة والتوصيات}

تعرضت هذه الدراسة إلى مـوضوع هام من مـوضـوعـات التنميـة ألا وهو التنمـيـة السيـاخيـة

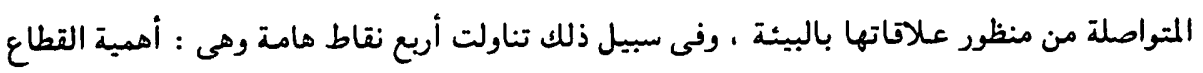
السياحى من الناحية الاقتصادية والاجتماعية وعلاقاته المباشرة وغير المباشرة بغيره من القطاعات ، ويعد ذلك تناولت العلاقات التأثيرية المتبادلة بين السيـاحة والبيـة، ثم قامت بتحليل العلاحة بين البيئة والمغريات السياحية ـ. وأخيرا تعرضت للموضوع الملح فى هذا الوقت وهو التنمية السياحية المتواصلة واهم أهدافها

وتوصلت الدراسة لعدة توصيات ترى انها هامة فى سبيل تحقيق التنميـة السياحية المتواصلة والمتوافقة مع البيئة وهى :

(1) تعـيق الدراسات المناصة بقطاع السياحة من حيث ارتباطه بالبيـنة المحيطة وحساسيته

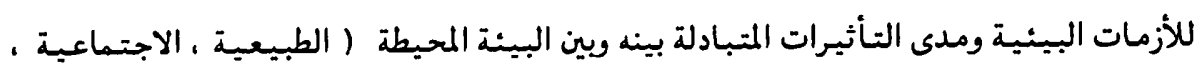
المصنوعة )

(Y) ينبـنى أن يحافظ النشاط السيـاحى على البيـــة وعلى عناصرها من ماء وهواء وترية وكائنات نباتية وحيوانية من أى تدهور أو تلوث أو سوء استغلال حيث إن البيثة النظيفة والسليمة

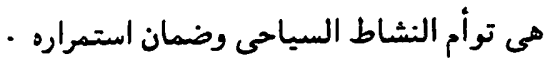
(r) ضرورة التعاون الوثيت بين وزاره شئون البيئة والأجهزة التابعة لها وبين وزاره السياحة

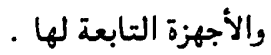

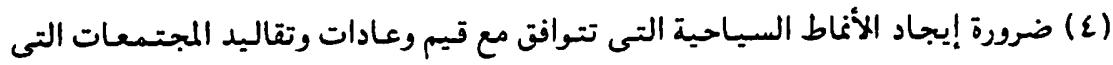
تقام بها وذلك للمحافظة على البيـة الاجتـماعية والثقافيـة وذلك فى حد ذاته يمكن أن يثرى بدوره العملية السياحية .

(0) العمل على نشر الوعى البينى وكيفية حماية البيـنة وترشيد استخدام الموارد والحفاظ عليها ، مع التثقيف البيئى المستمر ل (7) التنسيت بِن القطاعات المختلفة للدولة لحماية الثروات الطبيعية من التشويه والتعدى التحى والتلوث البيئى بحتتلف أشكاله مع المحافظة على الثروات القومية . 
تمية الوعى السياحى لدى الشعب من خلال وسائل الاتصال الإعلامى والثقافى والتوعية فى المدارس والجامعات بأهمية السياحة ودورها فى خدمة الاقتصاد القومى، وكذلك كيفية معامله

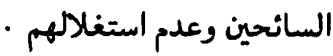

(1) تطوير برامج التعليم السـيـاحى مع ريطه بالتعليم البـــى والاهتـــام بتـدريب الكوادر

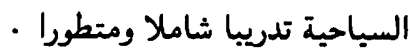

(9) إنشاء مركز متخصص لإدارة الأزمات فى قطاع السياحة يعمل بكافة الأساليب العلمية والتكنولوجيه الحديثة.

\section{المراجع}

1- تطوير اسـاليب وتواعد المعلومات فى ادارة الأزمـات المهددة لاضطراد التنـيـة (مرحلة

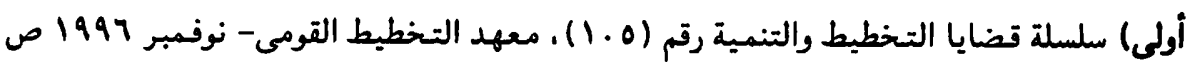

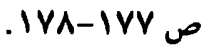

r- اتتصاديات التطاع السياحى فى مصر وانعكاساتها على الاتتصاد القومى - سلسلة

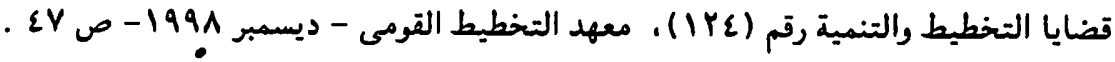
r- عصر من السياحة ، وزارة السياحة ، القاهرة ، 1994 ، ص 94 1.

ع- بنك الاسكندرية : النشرة الاتتصادية - المجلد الرابع والعشرون - القاهرة "

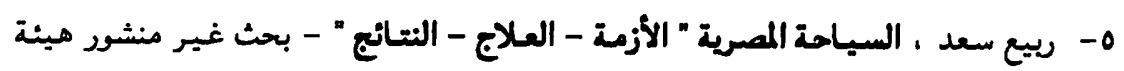

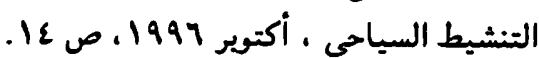
צ- - المرجع السابق ، ص ro ro.

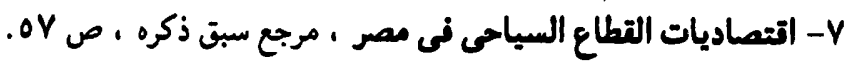

8- A.M. Freeman \& Others : The Economics of Environmental policy, (Joh-Wiley \& INC, New York,London ,1991).P19.

9- Ian Burton, Robert W.Kates \& Gilbert. F.White, The Environment as Hazard (New York,Oxford University Press,1978. P.31.

• 1- محمد عبد الفتاح القصاص - الإنسان والبيئة والتنمية - كتاب المؤتر الدانى لللراسات 
والبحوث البينية ، القاهرة - أكتوير - نوفمبر 1991 ، ص ص ـ999.

، 11- وفاء أحمـد عبد الله - حول العلاقة بين السياحة والبينة المعاصرة - مؤتمر التنمية السياحية والمفاظ على البينة واستخدامات الطاتة البديدة والمتجلدة فى جهاز شئون البيتة - مؤسسة

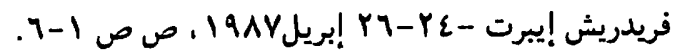

rا - إيمان محمد منجى : ترشيد اتخاذ القرارات الادارية لمواجهة الازمات فى تطاع السياحة

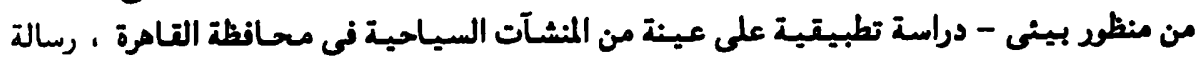

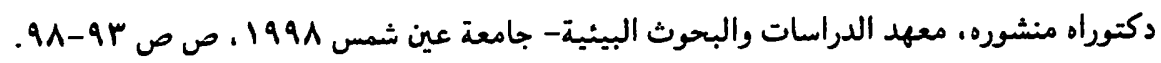

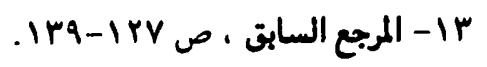

ع أ صلاح الدين عبد الوهاب - الكتاب السنوى للسياحة والفنادق - الجمعية المصرية لخبراء

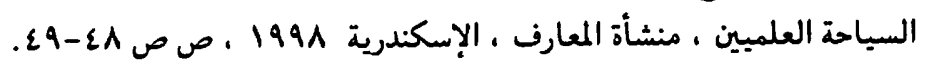

